\title{
Reduction of Patients' Congestion in Nigerian Hospitals
}

\author{
Tochukwu Arinze Ikwunne ${ }^{1}$, Samuel Obiora Okide ${ }^{2}$ and Moses Okechukwu \\ Onyesolu $^{3}$ \\ ${ }^{1}$ Department of Mathematics/Computer Science/Statistics/Informatics, Federal \\ University Ndufu-Alike, Ikwo, Nigeria \\ ${ }^{2,3}$ Department of Computer Science, Nnamdi Azikiwe University Awka, Nigeria \\ Itochukwuikwunne@yahoo.com, ${ }^{2}$ samuelokide@yahoo.com, \\ 33o.onyesolu@unizik.edu.ng
}

\begin{abstract}
Waiting for public healthcare services in Nigerian hospitals have increased considerably as a result of the economic crisis. This has resulted to congestion of patients' and delays for medical services particularly at the out-patient department of these hospitals. The World Health Organization has a target for doctors to population ratio. However, the rate at which patients wait for medical services at the Outpatients Department (OPD) of Nigerian hospitals makes congestion a recurring decimal. In this paper, we sought to determine the minimum waiting costs for patients' to receive a medical attention and service costs of the hospitals by determining the required number of doctors. Thenceforth, time specific system is introduced in order to reduce patients' congestion. This was achieved by using multi-server queuing model to study and analyse the queuing characteristics of two hospitals in Nigeria. Production and operations management, quantitative and qualitative methods were employed in the study. In addition, object oriented analysis and design methodology (OOADM) was employed in developing an application for this work. The results of the study demonstrated that congestion can be minimized by providing time-specific system and reducing the overutilization of doctors at the hospitals at a minimum costs as against their present state.
\end{abstract}

Keywords: Patient support, queuing, doctor, high level diagram, time specific appointment system

\section{Introduction}

Congestion is an excessive overcrowding in which processes are slowed by under capacity of critical resources along the delivery pathway. Congestions are ubiquitous, particularly in healthcare delivery systems. Congestions are undesirable because it result in delay in receiving needed services and can cause prolonged discomfort. This can result to costs to patients' and possible worsening of their medical conditions that can increase subsequent treatment costs and poor health outcomes. Given the negative consequences of congestions in hospitals, the following questions naturally arise. Why does congestion form? Why must patients wait to be served? Which features of system design affect congestion and by how much? What trade-offs must be considered by a service system architecture when choosing system parameters in order to reduce congestion? [1].

In any case, congestions are formed when entities (patients') that request service arrive at service facility and cannot be served immediately upon arrival. In an ideal world, no patient would ever want to wait to see a doctor, thus erasing the necessity of a waiting room. However, in today's ever increasingly busy medical hospitals, waiting time is an unavoidable reality, so identifying ways to improve or reduce waiting time would be ideal, considering the many negative consequences of increased waiting time [2]. A recent study has shown that $97 \%$ of patients' are frustrated by long waiting times in the hospital 
[3] and always have the notion that they will spend a lot of time whenever they visit the hospital. Similarly, long waiting time is common in most general outpatient clinics in Nigeria [4-5]. Moreover, wait times for medically necessary healthcare can result in costs on waiting patients, as well as their relatives and friends. Wait times impose medical risks, including deterioration while waiting, adverse events, irreparable impacts on health, and sometimes death. Waiting time often leads to important personal costs including reduced quality of life and depression. The impact of waiting varies by condition. For conditions such as heart diseases, diseases of the circulatory system, and cancer, long wait times as a result of congestion can often lead to serious sudden adverse events, disability, or even death. For orthopaedic surgeries, long wait times may have a significant impact on quality of life, mental and emotional well-being. For some conditions, long waits may carry less serious risks, although there may still be some harm in terms of personal costs.

There are three major factors contributing to this long waiting time in the hospital. The first factor is the difference between the number of patients demanding for medical attention daily and the available capacity to meet the demand. The second factor has to do with the high number of patients that are visiting the hospital daily without prior appointments and, as a result, have to wait for a longer time than expected to receive medical attention. The third factor is that the demand for specialist doctors' service often exceeds supply (the number of doctors available) [6].

This paper contributed in addressing these problems in two major ways:

1. Investigation was made to know the flow of patients' in the outpatient department (OPD) in each of the two hospitals studied (University of Nigeria Teaching Hospital (UNTH) Ituku Ozalla and Federal Medical Center (FMC) Owerri). Queuing theory was applied to determine and model the queuing characteristics at the hospitals and the optimal number of doctors required to provide optimum service (reduced waiting time to the patients' and service cost to the hospitals). On a more specific note, the optimum total costs (waiting and service costs) and required number of doctors to improve both patient satisfaction about their waiting time and associated cost and the service rendered by the doctors was determined. This is because, patients have to wait for a long time before seeing their doctors, as long as the imbalance in the doctor-patient ratio is not addressed.

2. The researchers argued that it is not adequate for most hospitals to respond to delays in medical services to patients by adding more beds, building, equipment, doctors or transferring patients to other hospitals or refusing to admit patients without considering the optimal number of doctors required to provide optimum service (reduce the waiting time of patients and service cost to the hospital), as the only way to deal with the delays and an increasing population of the patients. Lack of a time-specific appointment has been suggested the only reason for patients' delay [4], this has not been the usual practice in most outpatient clinics in Nigeria. Patients' arrive the OPD within the same time block (07:00 to 10:00 hours). Because of this, physicians get so overwhelmed with the large number of patients' requiring service [7]. However, recent works that examined the factors leading to delays suggests otherwise [8-9]. In many cases, delays are not a resource problem; they are a flow problem. Improving patient flow not only reduces delays and waittimes, an efficient flow of patients ensures that patients receive safe and timely care while preserving the effective use of staff time and hospital resources.

Therefore, it was observed that before introducing time-specific appointments in the healthcare system, the optimal number of doctors required to provide optimum service should be first determined using an appropriate queuing model. Hence, to deal with the uncertainty in the distribution of demand for hospital services, there is a need to forecast fluctuations in demand and plan supply accordingly. It must also be able to respond flexibly to fluctuations in the distribution of demand for hospital services. The implication of this is that delays may not be a capacity problem but a system problem. 


\subsection{Existing Problem}

Nigeria healthcare is riddled with delays and congestion of patients. Patients have to wait for long upon arrival to the hospital before they can access a doctor. Long waiting time can affect patients by creating a low compliance with medical procedures and the doctor's recommendations, deterioration and dissatisfaction with their care and unwillingness to visit the hospitals even when seriously ill. Hospitals are increasingly challenged to reduce these inherent waits and delays in moving patients into and out of the hospital. Hence, establishing a queuing model for patients can reduce extensive waits and improve the overall flow of patients in the hospitals.

\subsection{Design Objective}

The design objectives of this work is to develop an optimized quality health service system that enhances optimal time duration between patients appointments at a reduced cost and number of doctors in order to reduce waiting time of patients at the OPD of hospitals. This will be achieved by (a) Scheduling patients using a time-specific appointment system. (b) Determine the optimal number of doctors required, by determining the optimal costs to provide optimal services in order to reduce the waiting costs to the patients' and the service costs to the hospitals. Provide optimum allocation of rooms to the patients' to receive medical services.

\section{Literature Review}

Hospitals, like many service firms, operate under uncertainty about future demand for their services. Hospitals must abridge in advance for labour, technology, support services, and other inputs. They face the risk that the capacities of the inputs they abridge for any future day are too large, resulting in inefficiency, or too small, resulting in congestion. If patients' arrival and service time are known in advance, the operation of facility or facilities will be scheduled in a manner that would eliminate waiting completely [10].

Hodge et al. [11] reviewed studies on the consequences of waiting too long for cataract surgery. They determined that patients who endure extended waits experience more vision loss, a reduced quality of life, and are at greater risk of falls. In the same vein, Boisjoly et al. [12] studied cataract surgery outcomes for a group of patients from 1999-2000 and compared them with those for a group of patients from 2006-2007 who experienced shorter delays. They found that those with shorter delays had better vision, less difficulty and fewer symptoms prior to surgery, and lower rates of accidents while waiting for care. Furthermore, the patients from the 2006-2007 group reported greater satisfaction after surgery and achieved significantly better visual function after surgery. Similarly, Plunkett, et al. [13] examined the consequences of wait times for emergency care. They found that longer delays from door to a unit and from a unit to ward were associated with increased risk of death within 30 days. This trend was across the entire spectrum of patients, from those most critically ill to those who were felt likely to survive.

Lean Six Sigma methodologies were utilized to redesign patients' flow processes [14]. There are three approaches to quality improvement in the healthcare industry to improve patients' satisfaction [15-16]. Smoothing the flow of patients' in and out of hospitals and other health care settings can help to reduce overcrowding, prevent poor handoffs, and avoid delays, all of which may worsen as more people gain access to insurance coverage and care [17].

The study of healthcare delay is an application of the discipline of queuing theory [18]. Health care is similar to other forms of queuing in these respects: the demand for service is in part predictable (e.g., result of time-of-day patterns) and in part random, health services require coordination of multiple resources, such as physicians, medications, and 
diagnostic equipment, services are provided in multiple steps, through a network of services, delays can be reduced through careful forecasting, scheduling, and process improvement and information management.

In the hospital setting, patients visiting the hospital for treatment and check-ups are known as arrivals which are generated on time by an input source randomly from finite or infinite population. These patients enter the queuing system and join a queue to be served. The total patient demand and required services from time to time constitute the size of arrival [19]. The provision of services using certain rule and the discharge of patients are referred to as departure processes. Departure in hospitals means discharge, or death [20]. At all time, a member of the patients on the queue is selected for service by some set of rules known as the queue discipline. The required service is then performed for the patient by the service mechanism, after which the customer leaves the queuing system [21].

Queuing theory is used as a means of optimizing the allocation of increasingly scarce resources. Queuing has the advantage of producing simple models using less data while including randomness and it also helps managers or administrators to determine the optimal supply of fixed resources necessary to meet a variable demand [22]. Recently, health policy formulators and hospital administrators have sought to apply queuing model in all facets of health care system [23]. The use of queuing network techniques allows the capturing of the stochastic nature of arrivals and service time that is typical in health care systems [24-25]. However, most proposed queuing methods lack real world validation and perhaps for this reason are yet to be embraced by most physicians and hospital receptionists [26].

\section{Materials and Methods}

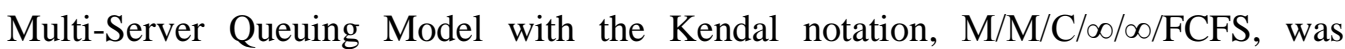
adopted to determine the optimum number of doctors required to achieve optimum service level which will guide the health and hospital administrator in restructuring and rescheduling their doctors to patients to achieve optimum service.

Where:

$\mathrm{M}$ represents a Poisson arrival distribution.

$\mathrm{M}$ represents an exponential service distribution.

$\mathbf{C}$ represents the number of servers in the same service facility

$\infty$ - capacity of the system (maximum queue length - infinite).

$\infty$ - number of potential customers in the given source population.

FCFS - the type of queue discipline, First Come, First Served

Object-Oriented Analysis and Design Model (OOADM) was also employed in developing an application for an optimized queueing model. The investigative phase of the OOADM was deployed as the paradigm for systematic study in order to obtain information on the current trends in the research area of queueing theory and its applications. The information obtained necessitated the definition of a high-level model (HLM) for the system as shown in Figure 1. OOADM was used to identify the objects needed in the system and their interrelationships. Adequate and relevant diagrams - class, use case, activity and entities relationship (E-R) - were generated which made the implementation quite easy and straight forward. Using the HLM, an optimized queueing model was implemented.

Other methods employed are:

1. Observation: This method was employed to witness firsthand operations of the hospital system under study. How the existing health services operates daily, particularly, how patients information are retrieved, stored and updated; patients arrival rate, service rate and number of servers were observed.

2. Evaluation and Documentary Review: This method provided a central location on how patients and specialists data are stored. Some documents were inspected 
in the hospitals, these include patients flow record, specialist record and cash flow record.

3. Interview: This method helped in getting resource materials for optimized health system and reference materials.

It was discovered and assumed that these queuing systems at the UNTH and FMC have the following: (a). the number of patient's arrivals follows a Poisson probability distribution at an average rate of $\lambda$ patients per hour. (b). the queue discipline is First Come, First-Served (FCFS) basis by any of the servers. (c). service time is exponentially distributed, with an average rate of $\mu$ patients per hour. (d). infinite number of queue. (e). the service providers are working at their full capacity. (f)The average arrival rate is greater than average service rate. (g). servers here represent specialist doctors. (h). service rate is independent of queue length.

\section{A. High Level Model (HLM) of the System}

The HLM of the system (Figure 1) is made up of three modules: File, Specialist Doctors and Patients. Each module is also divided in to sub modules. The different sub modules are: Registration, Membership Card, Payments, Book Room, Appointment, Deposit, check In, Complete Payment and Check Out.

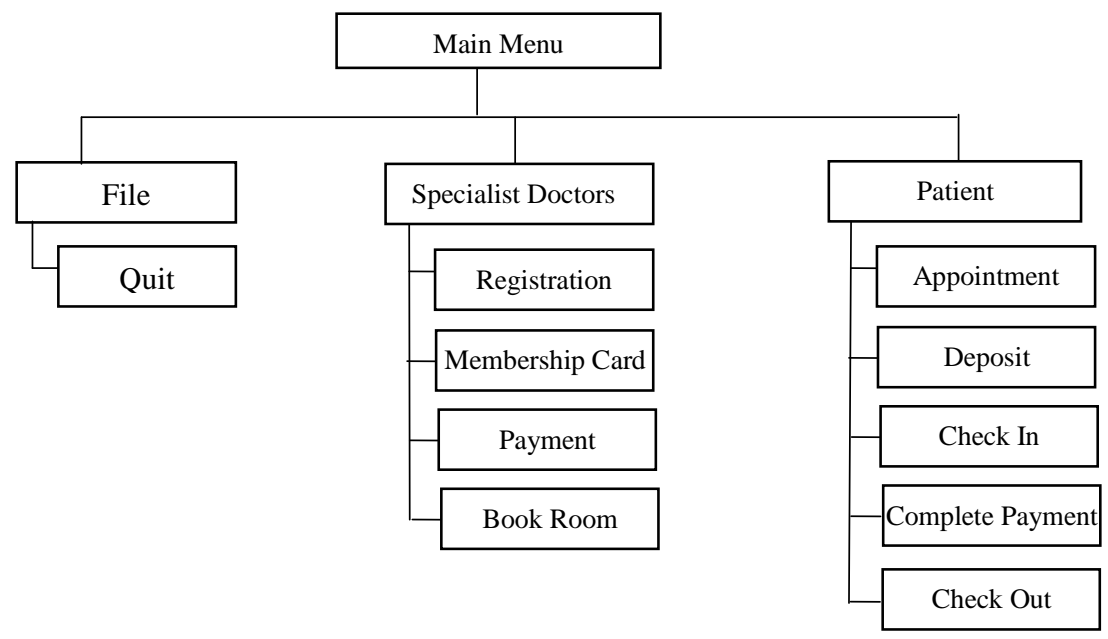

Figure 1. High Level Model of the System

\section{B. Analysis of the Multi-Server Queuing Model}

It was assumed that patients' arrival follow a Poisson probability distribution at an average of $\lambda$ patients per hour. The service times are exponentially distributed; with an average of $\mu$ patients per hour and number of server $\mathrm{C}$. it is also assumed that the queuing discipline is FCFS basis. If there are $\mathrm{n}$ patients in the queuing system at any given time, then the following two cases may arise:

1. If $\mathrm{n}<\mathrm{C}$, (number of patients in the system is less than the number of doctor(s)), then there will be no queue. However, $(\mathrm{C}-\mathrm{n})$ number of servers will not be busy. Then, the combined service rate will be $\mu_{\mathrm{n}}=\mathrm{n} \mu ; \mathrm{n}<\mathrm{C}$.

2. If $n>=C$, (number of patients in the system is more than or equal to the number of doctors) then all servers will be busy and the maximum number of patients in the queue will be (n-C). The combined service rate will be $\mu_{n}=C \mu ; n>=C$.

From the model, the probability of having $\mathrm{n}$ patients in the system is given as:

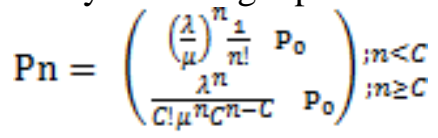


The probability that there is no patient in the system, that is, the servers are idle is determined using:

$$
\mathrm{P}_{0}=\left(\sum_{n=0}^{c-1} 1 / n !\left(\frac{\lambda}{\mu}\right)^{n}+1 / C !\left(\frac{\lambda}{\mu}\right)^{c} C_{\mu} / C_{\mu-\lambda}\right)^{-1}
$$

Next are the formulas for performance measures of the queuing system. The expected number of the patients waiting on the queue (queue length) is determined using:

$$
\mathrm{Lq}=\left(1 /(C-1) !(\lambda / \mu)^{C} \frac{\mu \lambda}{(\mu C-\lambda)^{2}}\right) \quad \mathrm{P}_{0}
$$

Expected number of the patients in the system is given as:

$$
\mathrm{Ls}=\mathrm{Lq}+\lambda / \mu
$$

Expected waiting time of patients in the queue is given as:

$$
W q=\frac{L q}{\lambda}
$$

Expected time a patient spends in the system is given as:

$$
W s=\frac{L s}{\lambda}
$$

System utilization (fraction of time the servers are busy) are

$$
\rho=\frac{\lambda}{\mu C}
$$

\section{Cost Analysis Model}

Two opposing costs (service costs and waiting time costs) must be considered in order to evaluate and determine the optimum cost and number of doctors in the system. The analysis of these costs help the management to make a trade-off between the increased costs of providing better service by the specialist and the decreased waiting time costs of patients, derived from providing that service [28].

Therefore, Expected Service Cost (ESC) is expressed as:

$$
\mathrm{ESC}=\mathrm{C} * \mathrm{C}_{\mathrm{c}}
$$

Where:

$\mathrm{C}=$ number of doctors, $\mathrm{C}_{\mathrm{c}}=$ service costs of each doctor.

Expected Waiting Costs (EWC) in the system is given by:

$$
\mathrm{EWC}=(\lambda * \mathrm{~W}) * \mathrm{C}_{\mathrm{w}}
$$

Where

$\lambda=$ arrival rate, $\mathrm{W}=$ expected time a patient spends in the system,

$\mathrm{C}_{\mathrm{w}}=$ Opportunity Cost of waiting by patients.

The Expected Total Costs (ETC) is the sum of ESC and EWC. Therefore adding (8) and (9), we have:

$$
\mathrm{ETC}=\mathrm{C} * \mathrm{C}_{\mathrm{c}}+(\lambda * \mathrm{~W}) * \mathrm{C}_{\mathrm{w}}
$$

\section{Data Analysis Model}

First, the optimal number of doctors required to provide optimum service was determined with their associated costs. Quantitative Methods, Production and Operation Management (POM QM) was used to compute the performance measures of the multiserver queuing system at the two hospitals investigated. As observed, UNTH has arrival rate $\lambda=300$ patients per hour, service rate $\mu=20$ patients per hour, number of doctors $\mathrm{C}$ $=16, C_{w}=\$ 1000$ per hour and $C_{c}=\$ 1500$ per hour. Similarly FMC has arrival rate $\lambda=$ 350 patients per hour, service rate $\mu=21$ patients per hour, number of doctors $C=18, C_{w}$ $=\$ 700$ per hour and $C_{c}=\$ 1000$ per hour. The same values were used in determining the performance measures of the existing system. Tables 1 and Table 2 show the performance measures of the two hospitals respectively in the optimized system. There was marked improvement in the performance measures in the optimized system.

Second, a sound patients' scheduler using a time-specific appointment system was developed. This is necessary in order to adapt to the future demand for medical services in 
the hospitals by patients. In addition, it will abridge in advance for number of doctors, technology, support services, and other inputs in order not to face the risk of abridging for too large inputs for any future day, resulting in inefficiency, or too small, resulting in congestion.

Table 1. Performance Measure of Multi-Server Queuing Model at the Unth

\begin{tabular}{cccccccc}
\hline $\mathrm{Z}$ & System Utilization & $\mathrm{P}_{0}=0$ & $\mathrm{~L}_{\mathrm{s}}$ & $\mathrm{W}_{\mathrm{s}}$ & $\mathrm{L}_{\mathrm{q}}$ & $\mathbf{W}_{\mathrm{q}}$ & $\begin{array}{c}\text { ETC } \\
(\mathbf{N})\end{array}$ \\
\hline $\mathbf{1 6}$ & 94 & 0 & 25.95 & 0.0865 & 10.95 & 0.0365 & $84,902.28$ \\
$\mathbf{1 7}$ & 88 & 0 & 18.9 & 0.063 & 3.9 & 0.013 & $73,804.08$ \\
$\mathbf{1 8}$ & $\mathbf{8 3}$ & $\mathbf{0}$ & $\mathbf{1 6 . 8 1}$ & $\mathbf{0 . 0 5 6 0}$ & $\mathbf{1 . 8 1}$ & $\mathbf{0 . 0 0 6 0}$ & $\mathbf{7 2 , 6 1 3 . 3 4}$ \\
$\mathbf{1 9}$ & 79 & 0 & 15.92 & 0.0531 & 0.92 & 0.0030 & $73,831.64$ \\
$\mathbf{2 0}$ & $\mathbf{7 5}$ & 0 & 15.48 & 0.0516 & 0.48 & 0.0016 & $75,962.58$ \\
\hline
\end{tabular}

Table 2. Performance Measure of Multi-Server Queuing Model at the Fmc

\begin{tabular}{cccccccc}
\hline Server & $\begin{array}{c}\text { System } \\
\text { Utilization }\end{array}$ & $\mathrm{P}_{0}$ & Ls & $W_{s}$ & Lq & Wq & $\begin{array}{c}\text { ETC } \\
(\mathbf{N})\end{array}$ \\
\hline $\mathbf{1 8}$ & 93 & 0 & 25.02 & 0.0715 & 8.35 & 0.2386 & $59,357.42$ \\
19 & 88 & 0 & 20.10 & 0.0574 & 3.44 & 0.0098 & $54,476.3$ \\
20 & $\mathbf{8 3}$ & $\mathbf{0}$ & $\mathbf{1 8 . 3 6}$ & $\mathbf{0 . 0 5 2 5}$ & $\mathbf{1 . 6 9}$ & $\mathbf{0 . 0 0 4 8}$ & $\mathbf{5 4 , \mathbf { 0 3 3 . 5 4 }}$ \\
21 & 79 & 0 & 17.56 & 0.0502 & 0.89 & 0.00254 & $54,914.93$ \\
$\mathbf{2 2}$ & 76 & 0 & 17.15 & 0.0490 & 0.48 & 0.00137 & $56,344.05$ \\
\hline
\end{tabular}

\section{Results and Discussion}

The result of this work is an optimized queuing system which helps reduce patients' congestion in Nigerian hospitals. The system manages the number of patients arrival, the service time and the number of server in order to reduce their waiting times for medical services; has a database that stores specialist and patients records; makes time-specific appointments; generate specialists' and patients' report and handles the availability of room and room booking at any time during the year but subject to availability. Therefore, a new approach to reducing patients' congestions at the hospitals by reducing patients' waiting cost and determining an optimal number of doctors to administer the required services to the patients' with a minimum cost and integration of time-specific appointment were achieved.

On a more specific note, the optimal total costs (waiting and service costs) and staffing levels (specialist doctors) required to improve both patient satisfaction were determined and optimized (Table 1 and Table 2) for UNTH and FMC Owerri respectively. For UNTH in Table 1, it is evident that ETC is optimum at a given number of doctors $(\mathrm{C})$ and that patients' delay and expected waiting time in the system are less at the determined optimum number of doctors. It also showed that the ETC initially decreased and at a given point started increases with a given number of doctors. The lowest expected total cost is 72, 613.34 with an optimized number of 18 doctors and the waiting time in the system and queue are $\mathbf{0 . 0 5 6 0}$ and $\mathbf{0 . 0 0 6 0}$ respectively. The utilization factor decreases with decreasing patients' waiting time in the queue until it gets to an optimum utilization factor of $\mathbf{8 3 \%}$ against the optimum $\mathbf{0 . 0 0 6 0}$ waiting time in the queue; utilization factor decreased to an optimum point of $\mathbf{8 3 \%}$ as the number of doctors increases to an optimum number of $\mathbf{1 8}$ doctors. Furthermore, the utilization factor increased as the average waiting time in the system increased respectively. 
Similarly for FMC in Table 2, ETC initially decreased and at a point increased with increasing number of doctors. The lowest expected total cost is $\$ \mathbf{5 4}, \mathbf{0 3 3 . 5 4}$ with an optimized number of $\mathbf{2 0}$ doctors and the waiting time in the system and queue are $\mathbf{0 . 0 5 2 5}$ and $\mathbf{0 . 0 0 4 8}$ respectively. The utilization factor $\rho$ decreased with increasing patients' waiting time in the queue with an optimum utilization factor is $\mathbf{8 3 \%}$ against the optimum $\mathbf{0 . 0 0 4 8}$ waiting time in the queue and the utilization factor decreased as the number of doctors' increased to the optimum number of $\mathbf{2 0}$.

\section{Conclusion}

Decisions involving the design of waiting lines are based on a subjective evaluation of the operating characteristics of the waiting line. The cost of operating a waiting line system is determined based on the decision regarding the system design on a minimum operating cost, because in business cost is minimized and profit maximized. An optimized system that reacted to fluctuations in the distribution of demand for hospital services from the application of queuing theory was provided. This was achieved by developing a time specific system that checks the availability of date, time and specialist doctors whenever patients want to make appointment to receive a medical treatment from the hospital. The rapid high number of patients that are visiting the hospitals daily without prior appointments outweighs the number of medical staff. Researchers' focus is to manage the patients' congestion and make them feel satisfied. The old system is characterized by lengthy wait times, delay in retrievals of patients' history which result to waiting cost and affect patients by creating low compliance with the doctor's recommendations and dissatisfaction with their care. The problems of the old system were identified and an optimized system designed and developed. This will help to solve the identified problems. Therefore, the result obtained from the new system can be used in enhancing the overall effective and efficient growth of the hospitals and help the management in decision making.

\section{References}

[1] B. T. Denton, "Handbook of Healthcare Operations Management: Methods and Applications, International Series in Operations Research and Management Science" 184, Springer Science+ Business Media, New York, (2013).

[2] C. J. Hill and K. Joonas, "The impact of unacceptable wait time on healthcare patients' attitudes and actions", Health Mark Quartely; vol. 23, no. 2, (2005), pp. 69-87.

[3] D. Doyle, "Five tips to reduce patient dissatisfaction with wait times". Retrieved: January 11, 2014 from http://www.physicianspractice.com/blog/five-tips-reduce-patient-dissatisfaction-wait-times, (2014).

[4] I. O. Ajayi, "Patients' waiting time at an outpatient clinic in Nigeria—can it be put to better use? Patient Education and Counseling", vol. 47, (2002), pp. 121-126.

[5] T. D. Thatcher, "Outpatient waiting time in Jos University Teaching Hospital (JUTH)", Highland Med Res. J, vol. 3, (2005), pp. 36-42.

[6] C. K. Cavas and L. Cavas, "Application of Queuing Theory to the Relationships between Insulin Level and Number of Insulin Receptors", Turkish Journal of Biochemistry, vol. 32, no. 1, (2007), pp. 32-38.

[7] O. Ogunfowokan and M. Mora, "Time, expectation and satisfaction: Patients' experience at National Hospital Abuja, Nigeria", Afr J Prm Health Care Fam Med. vol. 4, no. 1, (2012).

[8] C. Rudin and G. Vahn. "The big data newsvendor: Practical insights from machine learning analysis", Working Paper, (2014).

[9] J. Dong, E. Yom-Tov and G. B. Yom-Tov, "The impact of delay announcements on hospital network coordination and waiting times", Working Paper, (2015).

[10] A. R. Adeleke, C. E. Adebiyi, and O. Akinyemi, "Application of Queuing Theory to Omega Bank PLC, Ado Ekiti”, International Journal of Numerical Mathematics vol. 1, no. 122, (2005), pp. 129.

[11] W. Hodge, T. Horsley, D. Albiani, J. Baryla, M. Belliveau, R. Buhrmann, M. O’Connor, J. Blair and E. Lowcock, "The Consequences of Waiting for Cataract Surgery: A Systematic Review". Canadian Medical Association Journal 176 vol. 9, (2007), pp. 1285-1290.

[12] H. Boisjoly, , E.E. Freeman, F. Djafari, M. Aubin, S. Couture, R.P. Bruen, R. Gizicki, and J. Gresset, "Reducing Wait Time for Cataract Surgery: Comparison of Two Historical Cohorts of Patients in Montreal”. Canadian Journal of Ophthalmology vol. 45, (2010), pp. 135-139. 
[13] P.K. Plunkett, D.G. Byrne, T. Breslin, K. Bennett, and B. Silke, "Increasing Wait Times Predict Increasing Mortality for Emergency Medical Admissions". European Journal of Emergency Medicine vol. 18, (2011), pp. 192-196.

[14] Institute for Healthcare Improvement, Going Lean in Health Care. IHI Innovation Series. Available at: www.IHI.org - See more at: http://www.centrallogic.com/resources/patient-flow-journal/scholarshiprecipient-strategies-to-enhance-patient-flow\#sthash.MdZVDEW7.dpuf, (2005).

[15] E.J. Torres and K.L. Guo, "Quality Improvement Techniques to Improve Patient Satisfaction" International Journal of Health Care Quality Assurance, vol. 17, no. 6, (2004) p. 334-338.

[16] M.J. Wilson and K. Nguyen "Bursting at the Seams: Improving Patient Flow to Help America's Emergence Departments" Urgent Matters/George Washington University Medical Center. Available at http://urgentmatters.org/media/file/reports_UM_WhitePaper_BurstingAtTheSeams.pdf. (2004)

[17] M. Hostetter and S. Klein, "In Focus: Improving Patient Flow-In and Out of Hospitals and Beyond"Commonwealth fund newsletters: available at http://www.commonwealthfund.org/publications/newsletters/quality-matters/2013/october-november/infocus-improving-patient-flow, (2013)

[18] R. W. Hall, "Patient Flow: Reducing Delay in Healthcare Delivery". Springer, (2006)

[19] Y. Tutunci and D. Newlands, "Hospital Bed Capacity and Mix Problem for State Supported Public and Fee Paying Private Wards", Economic and Management, IESEG, School of Management, CNRS-LEM (UME 8129), (2009).

[20] D. Smith and L Mayhew, "Using Queuing Theory to Analyze Governments Completion Time Target in Accident and Emergency Departments", Health Care Management Science, vol. 11, (2008), pp. 11-21.

[21] S. F. Hiller and J. G Lieberman, "Introduction to Operations Research, Boston", McGrow Hill, Eight Edition, (2005).

[22] M. C. McManus, M. C Long, A. B. Cooper and E. Litvak, "Queuing Theory Accurately Models the Need for Critical Care Resources", Anesthesiology, vol. 100, no. 5, (2004) pp. 1271-1276.

[23] A. Bagust, M. Place and J. W. Posnett, "Dynamics of Bed use in Accommodating Emergency Admissions; Stochastic Simulation Model”, BMJ, vol. 329, (1999), 155-163.

[24] N. Koizumi, E. Kuno and E. T. Smith, "A Queuing Network Model with blocking: Analysis of congested patient flow in mental Health System", Health Care Management Science, vol. 8, no. 1, (2005), pp. 49-60.

[25] C. Osorio and M. Bielaire. "Describing Network Congestion with an Analytic Queuing to Network Model", Swiss Transport Research Conference, (2007).

[26] A. X. Costa, S. A. Riddely, A. K. Shahani, P. R. Harper, V. Desenna and M. S. Nielsen, "Mathematical Modelliing and Simulation for Planning Critical Care Capacity", Anesthesia; vol. 58, no. 1, (2003), pp. 320-329.

[27] G. Bolch, S. Greiner, H. de Meer and K. S Trivedi, “Queueing Networks and Markov Chains: Modeling and Performance Evaluation with Computer Science Applications", John Wiley \& Sons, (2001), pp. 209-262.

[28] M. M. Kembe, E.S. Onah and S. Iorkegh, "A Study of Waiting and Service Costs of a Multi-Server Queuing Model in a Specialist Hospital”, Int. J. of Scientific \& Tech. Research; vol. 8, no. 3, (2012).

\section{Authors}

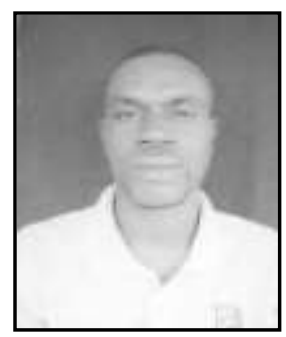

Tochukwu A. Ikwunne, A Graduate Assistant in the Department Computer of Mathematics/ Science/Statistics and Informatics, Federal University, Ndufu Alike, Ikwo, Ebonyi State and a postgraduate student pursuing a Master's Degree in Computer Science, Nnamdi Azikiwe University. He holds a Bachelor Degree in Computer/Statistics in University of Nigeria, Nsukka (2010). His interest is in persuasive technologies, optimization techniques and human computer interactions. He has published a book entitled -ICT for a Greener Environment, A Case for Nigeria (Nsukka, Enugu: Great Ap Express Publisher Ltd: 2014). He is a member of Industrial Safety Security of Nigeria (ISSN).He has received a specialized training in working safely from Institute of Occupational Safety and Health (IOSH). 

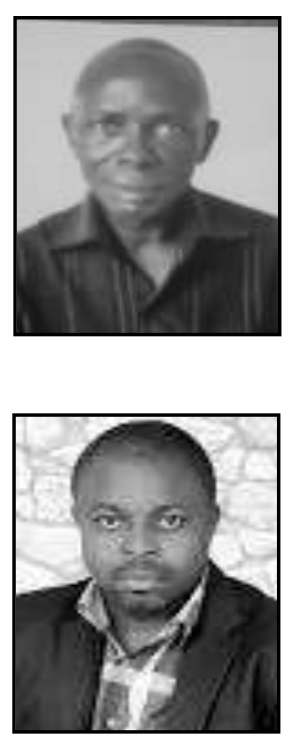

Samauel Okide's, research interest is on algorithms and complex system. He has Ph.D., M.Sc. and B.Sc. (Computer Science) from Nigeria and he works as a senior lecturer and researcher in Nnamdi Azikiwe University Awka. He has published widely in his research areas. He is a member of the following learned societies: Computer Professionals (Registration Council of Nigeria) (CPN), and International Association of Computer Science and Information Technology (IACSIT).

Moses O. Onyesolu, Has Ph.D. (Virtual Reality), M.Sc. B.Sc. (Computer Science) from Nnamdi Azikiwe University, Nigeria where he works as a lecturer and researcher. He was the Head, Department of Computer Science, Nnamdi Azikiwe University (September. 2014 to January, 2017). His research interests are mainly in computer modeling and simulation, e-learning/virtual reality technologies, queueing system/theory and its applications. He has published widely in these areas. $\mathrm{He}$ is a member of the following learned societies: Nigerian Computer Society (NCS), Computer Professionals (Registration Council of Nigeria) (CPN), International Association of Engineers (IAENG), International Association of Computer Science and Information Technology (IACSIT) and European Association for Programming Languages and Systems (EAPLS). 